\title{
A Facile Synthesized Polyaniline Coated Zerovalent Iron-Silica as an Efficient Sorbent for Magnetic Solid Phase Extraction of Phenolic Pollutants in Water Samples
}

\author{
Jirasak Gamonchuang, ${ }^{a}$ Kate Grudpan ${ }^{b}$ and Rodjana Burakham ${ }^{\circledR} * a$ \\ ${ }^{a}$ Materials Chemistry Research Center, \\ Department of Chemistry and Center of Excellence for Innovation in Chemistry, \\ Faculty of Science, Khon Kaen University, 40002 Khon Kaen, Thailand \\ ${ }^{b}$ Department of Chemistry, \\ Faculty of Science and Center of Excellence for Innovation in Analytical Science and Technology, \\ Chiang Mai University, 50200 Chiang Mai, Thailand
}

\begin{abstract}
A magnetic material based on polyaniline coated zerovalent iron-silica (Fe@ $\left.\mathrm{SiO}_{2} @ \mathrm{PANI}\right)$ was simply synthesized using a facile manner under low energy consumption and applied for magnetic solid phase extraction of phenolic pollutants prior to analysis by high performance liquid chromatography-photodiode array detection (HPLC-PDA). The parameters which affected the extraction efficiency, i.e., sorbent amount, extraction time, sample volume and $\mathrm{pH}$, desorption solvent and its volume, were optimized. Wide linear dynamic range of 0.012-10.000 $\mu \mathrm{g} \mathrm{mL}-1$ and the coefficients of determination better than 0.9926 were achieved. The limits of detection and the limits of quantitation were found in the ranges of $0.001-0.030$ and $0.012-0.090 \mu \mathrm{g} \mathrm{mL}^{-1}$, respectively. The precision, expressed as relative standard deviation (RSD), was better than $11 \%$. The synthesized sorbent exhibits good adsorption affinity and reusability up to 16 cycles. Applicability of the proposed methodology for analysis of phenolic residues in environmental and wastewater samples showed the recoveries in the range of $83.4-118.9 \%$.
\end{abstract}

Keywords: zerovalent iron, polyaniline, phenol, magnetic solid phase extraction, HPLC

\section{Introduction}

Exposure of toxic chemicals in the environment is one of the serious issues worldwide. Phenol and its derivatives are increasingly released into agricultural production regions or the aquatic environment during industrial processes, i.e., paper, dye, textile, plastic, and pharmaceutical production. ${ }^{1,2}$ They are classified as priority pollutants by the European Union (EU) and the United States Environmental Protection Agency (US EPA). The presence of phenolic pollutants can cause long-term damaging effects in living organisms and carcinogenic potential to humans. Therefore, monitoring the concentration of phenol compounds in the environment is of great importance and can make relevant regulations for phenol emission to prevent environmental pollution.

Separation techniques, including high performance liquid chromatography (HPLC), ${ }^{3-5}$ and gas chromatography (GC), ${ }^{6,7}$ have been reported for simultaneous determination of these pollutants. However, direct analysis is quite

*e-mail: rodjbu@kku.ac.th difficult due to their low concentration levels present in complex matrices. Hence, significant effort is paid on development of various sample pretreatment techniques for potential enrichment of the target analytes prior to analysis by instrumentation techniques. The sorption-based extraction techniques have been given attention in analytical chemistry community because of some greater advantages over the liquid-phase extraction techniques, including simple procedure, less consumption of toxic organic solvent, and a variety of solid sorbents available covering a large number of chemical functionalities. ${ }^{8}$ The type of solid sorbent has great impact on the extraction performance of the method because it determines the sorption ability to enrich the target analytes from the sample matrices.

Recently, a dispersive solid phase extraction (DSPE) has been introduced and applied to extract various compounds. ${ }^{8,9}$ The technique is based on direct dispersion of the solid sorbent in a sample solution to allow the selective extraction of the target analytes to the sorbent. After that, the analyte-adsorbed sorbent was separated from the solution by centrifugation (or filtration) before eluting 
the analytes from the sorbent using a suitable desorption solvent. The DSPE technique offers some advantages over the conventional solid phase extraction (SPE) approach, including simple and rapid extraction process, low toxic organic solvent consumption, and no cartridge or disk needed. ${ }^{9}$ Recently, a modified DSPE method has been released based on using magnetic particles (MPs) as sorbent, called magnetic solid phase extraction (MSPE). A unique and superior feature of MSPE over DSPE is that magnetic sorbent can rapidly be isolated from sample solutions by simply applying external magnetic field to avoid centrifugation or filtration of the sample. ${ }^{10}$ The method has the advantages of high extraction efficiency, simple separation process, environmentally friendly and excellent reusability of the sorbent. ${ }^{11}$ The efficiency of MSPE generally depends on the design of magnetic sorbent to bind well with the target analytes. Several kinds of magnetic sorbents have been synthesized and widely used for analytical applications, including functionalized magnetic nanoparticles, ${ }^{12,13}$ magnetic carbon nanotubes, ${ }^{14,15}$ magnetic metal organic framework (MOF), ${ }^{16-18}$ magnetic graphene oxide, ${ }^{19,20}$ and magnetic molecular imprinted polymer. ${ }^{21-23}$

Zerovalent iron nanoparticles has attracted much interest as magnetic material of choice for MSPE technique due to their high magnetization value, non-toxicity, costeffectiveness, easy preparation and modification. ${ }^{24-28}$ However, the application of bare zerovalent iron in MSPE technique have some limitations, i.e., low selectivity for the target analytes, easy oxidation, low acid resistance and high aggregation as well as low dispersibility in sample solution. ${ }^{29,30}$ To reduce their limitations and improve an adsorption capability for the target analytes, modification of zerovalent iron surface is intensely focused using several kinds of coating materials. ${ }^{31-33}$ Polyaniline (PANI) is one of promising coating polymers and has attracted a great deal of attention because its layer can provide active groups (benzene rings and amine groups) on the supporting solid surface that provide possible binding sites for the target compounds, including hydrophobicity, $\pi-\pi$ interaction, hydrogen bonding and electrostatic interaction. ${ }^{12,34-36}$ Moreover, it has additional advantages, such as good stability, low cost monomer, and facile synthesis. However, some polymerization processes of polyaniline can directly destroy magnetic materials by oxidizing its surface with the use of chemical oxidant during polyaniline formation process, causing reduction or loss of magnetic properties. Therefore, it is very necessary to improve stability of magnetic materials before modifying with polyaniline. Silica has gained wide attention because of its easy modification and high stability as well as good dispersibility in various media. ${ }^{37,38}$ The magnetic material using nanoscale zerovalent iron as the core coating with PANI shell ( $\mathrm{Fe} @ \mathrm{SiO}_{2} @ \mathrm{PANI}$ ) has been reported ${ }^{39}$ as sorbent for extraction of bisphenol A, tetrabromobisphenol A and 4-nonylphenol. The material shows excellent enrichment capability for the studied analytes. However, synthesis of the functionalized magnetic materials was carried out under unfavorable conditions, i.e., the use of an autoclave, high temperature, too long time and complicated steps. In addition, laborious extraction steps were not suitable for practical analysis.

Therefore, the purpose of this work was to synthesize the zerovalent iron-silica covered with polyaniline and develop simple method of MSPE for the determination of phenolic pollutants by HPLC. The silica coated zerovalent iron was simply prepared by sol-gel process with low energy consumption. Then, modification of polyaniline onto zerovalent iron-silica surface was proceeded through oxidative polymerization of aniline monomer. The morphological and magnetic properties of as-prepared sorbent were investigated. The experimental parameters influencing MSPE method, including sorbent amount, type of eluent and its volume, adsorption and desorption times, sample volume and sample $\mathrm{pH}$, were studied. The proposed methodology was applied for the analysis of phenolic residues in various water samples.

\section{Experimental}

\section{Chemicals}

All chemicals of at least analytical reagent grade were used in this experiment. Ferrous sulfate heptahydrate was obtained from Carlo Erba (Milan, Italy). Sodium borohydride and aniline were supplied by AppliChem (Mumbai, India), and Panreac (Bacelona, Spain), respectively. Ethanol was purchased from Merck (Darmstadt, Germany). Ammonium hydroxide was supplied by QRëC (Auckland, New Zealand). Cetyltrimethylammonium bromide (CTAB) was obtained from Ajax Finechem Pty Ltd. (NSW, Australia). Tetraethyl orthosilicate (TEOS) was purchased from Sigma-Aldrich (Steinheim, Germany). Ammonium peroxydisulfate was received from Analar Normapur (Leuven, Belgium). Phenol (Ph), 4-nitrophenol (4NP), 2,4-dichlorophenol (24DCP), 2-chlorophenol (2CP), 2,4-dinitrophenol (24DNP), 2,4-dimethylphenol (24DMP), 4-chloro-3-methylphenol (4C3MP), and 2,4,6-trichlorophenol (246TCP) were purchased from Sigma-Aldrich (Steinheim, Germany). Stock standard solutions of each phenolic compound (1000 $\mu \mathrm{g} \mathrm{mL}^{-1}$ ) were prepared by dissolving corresponding 
phenolic compound in methanol. Working solutions were prepared freshly in water. Deionized water (RiOs Type I Simplicity 185 water purification system, Millipore, St. Louis, USA) with a resistivity of $18.2 \mathrm{M} \Omega \mathrm{cm}$ was used in all experiments. Acetonitrile of HPLC grade (Merck KgaA, Darmstadt, Germany) was used for chromatographic separation.

\section{Instrumentation}

Fourier transform infrared spectra (FTIR) was obtained from a PerkinElmer Spectrum One FTIR spectrometer (standard $\mathrm{KBr}$ disk method) with wavenumber between 400 and $4000 \mathrm{~cm}^{-1}$. The crystal structure of the synthesized material was characterized by a PANalytical, EMPYREAN $\mathrm{X}$-ray diffractometer (XRD) with monochromatic $\mathrm{Cu} \mathrm{K} \alpha$ radiation $(\lambda=0.15406 \mathrm{~nm})$ in a $2 \theta$ range of 10 to $80^{\circ}$. The morphological information and particle size were examined using a FEI Helios NanoLab G3 CX dual beam scanning electron microscope with focused ion beam (FIB-SEM), and a FEI Tecnai $\mathrm{G}^{2} 20$ transmission electron microscope (TEM) with an accelerating voltage of $200 \mathrm{kV}$. CHN analyses were performed on a PerkinElmer PE 2400CHNS analyzer. Magnetic measurement was achieved by a VersaLab vibrating sample magnetometer (VSM) at $300 \mathrm{~K}$ with an applied magnetic field $(\mathrm{H})$ of $\pm 10000 \mathrm{Oe}$.

The HPLC system involved a 600E quaternary pump equipped with an inline degasser, a Rheodyne injector (10- $\mu \mathrm{L}$ sample loop), an ACE 5 C18 column $(4.6 \times 250 \mathrm{~mm}$, $5 \mu \mathrm{m}$, Advanced Chromatography Technologies Ltd.), a Waters 2996 photodiode array (PDA) detector (Waters, USA) operated at $280 \mathrm{~nm}$, and an Empower software for data acquisition. The analytes were separated under gradient elution of acetonitrile (solvent $\mathrm{A}$ ) and $0.1 \%$ acetic acid in water (solvent $\mathrm{B}$ ) as mobile phase, with a flow rate of $1.0 \mathrm{~mL} \mathrm{~min}{ }^{-1}$. The gradient programs are as follows: 0-3 min, $45 \%$ solvent A; 3-4 min, ramped to $55 \%$ solvent A; 4-8 min, held at 55\% solvent A; 8-9 min, ramped to $65 \%$ solvent A; 9-12 min, held at $65 \%$ solvent $\mathrm{A} ; 12-13 \mathrm{~min}$, ramped to $75 \%$ solvent $\mathrm{A}$; and $13-16$ min, held at $75 \%$ solvent A. After that solvent A was decreased to $45 \%$ before the next run.

\section{Synthesis of the sorbent}

\section{Preparation of zerovalent iron nanoparticles}

The zerovalent iron nanoparticles were synthesized according to the previous repor $\mathrm{t}^{40}$ with some modifications. In brief, ferrous sulfate $(5.56 \mathrm{~g})$ was dissolved in $400 \mathrm{~mL}$ water. Then, $100 \mathrm{~mL}$ of sodium borohydride solution $\left(0.4 \mathrm{~mol} \mathrm{~L}^{-1}\right)$ was added with vigorous stirring for $15 \mathrm{~min}$.
After that, the black solid was separated by external magnet before washing several times using water and ethanol, and finally dried in vacuum.

\section{Synthesis of polyaniline coated $\mathrm{Fe} @ \mathrm{SiO}_{2}$ particles}

The Fe@ $\mathrm{SiO}_{2}$ particles were synthesized via sol-gel method using TEOS as precursor, and then polyaniline coated $\mathrm{Fe} @ \mathrm{SiO}_{2}$ particle was prepared through oxidative polymerization of aniline in the presence of ammonium peroxydisulfate. The method was adopted according to the previous reports ${ }^{25,41}$ with some improvements. Firstly, the zerovalent iron nanoparticles $(50 \mathrm{mg})$ were dispersed in ethanol $(90 \mathrm{~mL})$, then water $(5 \mathrm{~mL})$ and ammonium hydroxide $(5 \mathrm{~mL})$ were subsequently added with sonication for $30 \mathrm{~min}$. Next, TEOS ( $1 \mathrm{~mL}$ ) was gradually dropped and the mixture was shaken for $24 \mathrm{~h}$ at ambient temperature. As-prepared $\mathrm{Fe} @ \mathrm{SiO}_{2}$ was collected by external magnet, washed with ethanol until the $\mathrm{pH}$ became 6-7. After that, the $\mathrm{Fe} @ \mathrm{SiO}_{2}$ particle was dispersed in water $(90 \mathrm{~mL})$ using ultrasonic bath, then $1 \mathrm{~mol} \mathrm{~L}^{-1} \mathrm{HCl}(2 \mathrm{~mL})$ and $\mathrm{CTAB}$ $(0.3 \mathrm{mmol})$ were slowly added keeping ultrasonication for $1 \mathrm{~h}$. Subsequently, the aniline was added slowly into the mixture and shaken for $1 \mathrm{~h}$ in an ice bath. Finally, $0.07 \mathrm{~mol} \mathrm{~L}^{-1}$ ammonium peroxydisulfate $(10 \mathrm{~mL})$ was gradually dropped and the mixture was shaken for $5 \mathrm{~h}$ in ice bath. The dark green of polyaniline coated $\mathrm{Fe} @ \mathrm{SiO}_{2}$ was collected by external magnet, washed several times with water and methanol, and dried. The product was defined as $\mathrm{Fe} @ \mathrm{SiO}_{2} @ \mathrm{PANI}$.

\section{Samples collection and preparation}

Environmental and wastewater samples were collected from different sites in northeastern area of Thailand. Two river water samples were taken from Chi River (Khon Kaen, Thailand), and Mekong River (Nakhon Phanom, Thailand). Four reservoir water samples were collected from Ubon Ratana Dam (Khon Kaen, Thailand), Lam Pao Dam (Kalasin, Thailand), Kaen Nakhon Lake (Khon Kaen, Thailand) and Nong Han Lake (Sakon Nakhon, Thailand). Three wastewater samples were collected from wastewater treatment plants in the university, hospital and textile industry. All collected samples were stored under cool condition $\left(4{ }^{\circ} \mathrm{C}\right)$ until analysis. The samples were filtered using nylon membrane $(0.45 \mu \mathrm{m})$ before applying the proposed method. The measured $\mathrm{pHs}$ of all water samples were between 6-7.

\section{MSPE procedure}

The sample solution $(25 \mathrm{~mL})$ was added into an extraction vial containing $\mathrm{Fe} @ \mathrm{SiO}_{2} @ \mathrm{PANI}$ sorbent 
(70 mg), and placed on vortex mixer for $2 \mathrm{~min}$. Then, the magnetic sorbent enriched with target analytes were collected by external magnet before decanting supernatant solution. Subsequently, desorption of analytes was carried out using $0.5 \mathrm{~mL}$ acetonitrile as desorption solvent and vortexed for $0.5 \mathrm{~min}$. The magnet was applied for $30 \mathrm{~s}$ to settle down sorbents. The supernatant was collected and filtered through a nylon membrane before further injecting into the HPLC system for analysis. The schematic extraction diagram is depicted in Figure 1.

\section{Results and Discussion}

\section{Characterization of $\mathrm{Fe} @ \mathrm{SiO}_{2} @$ PANI}

Functionalization of solid surface was characterized by FTIR. As shown in Figure S1 (Supplementary Information (SI) section), the FTIR spectrum of Fe exhibited the characteristic vibration peaks at 1067 , 685,562 and $470 \mathrm{~cm}^{-1}$, indicating the vibration mode of $\gamma$-FeOOH-lepidocrocite, $\mathrm{Fe}-\mathrm{O}$ stretching modes of the octahedral and tetrahedral sites, and maghemite $\left(\gamma-\mathrm{Fe}_{2} \mathrm{O}_{3}\right)$, respectively. ${ }^{42}$ In the FTIR spectrum of $\mathrm{Fe} @ \mathrm{SiO}_{2}$, the characteristic vibration peaks of both $\mathrm{Fe}$ and $\mathrm{SiO}_{2}$ were observed, which located at 1629, 1097, 950, 805, and $470 \mathrm{~cm}^{-1}$, assigned to $\mathrm{Si}-\mathrm{OH}$ bending, $\mathrm{Si}-\mathrm{O}-\mathrm{Si}$ asymmetric stretching, $\mathrm{Si}-\mathrm{OH}$ stretching, $\mathrm{Si}-\mathrm{O}-\mathrm{Si}$ symmetric bending and $\mathrm{Si}-\mathrm{O}-\mathrm{Si}$ bending, respectively. ${ }^{43}$ In this case, weak absorption peaks at $562 \mathrm{~cm}^{-1}$ for $\mathrm{Fe}-\mathrm{O}$ stretching mode was observed, confirming the coating of silica layer on Fe surface. ${ }^{33}$ The FTIR spectra of the $\mathrm{Fe} @ \mathrm{SiO}_{2} @ \mathrm{PANI}$ show the absorption bands at 1618, 1533, 1275, 1097, 950, 805,562 and $470 \mathrm{~cm}^{-1}$, which can be assigned to the $\mathrm{N}-\mathrm{H}$ bending, $\mathrm{C}=\mathrm{C}$ stretching, $\mathrm{C}-\mathrm{N}$ stretching for characteristic vibration bands of polyaniline, ${ }^{44} \mathrm{Si}-\mathrm{O}-\mathrm{Si}$ asymmetric stretching, $\mathrm{Si}-\mathrm{OH}$ stretching, $\mathrm{Si}-\mathrm{O}-\mathrm{Si}$ symmetric bending, $\mathrm{Fe}-\mathrm{O}$ stretching and $\mathrm{Si}-\mathrm{O}-\mathrm{Si}$ bending for vibration bands of silica and Fe. Therefore, the FTIR spectra confirmed the successful introduction of PANI into the surface of $\mathrm{Fe} @ \mathrm{SiO}_{2} \cdot{ }^{45}$

The XRD measurements were recorded for investigation of the phase and crystal structure of the $\mathrm{Fe} @ \mathrm{SiO}_{2} @ \mathrm{PANI}$ sorbents in the region of 10 to $80^{\circ}$. Figure $\mathrm{S} 2$ (SI section) shows the diffraction peaks of zerovalent iron at the $2 \theta$ of $45^{\circ}$, which were assigned to the presence of crystalline phase of zerovalent iron, according to the Joint Committee on Powder Diffraction Standard (JCPDS 87-0721). The presence of diffraction peaks at $32^{\circ}, 36^{\circ}, 57^{\circ}$ and $64^{\circ}$ corresponded to (220), (311), (511), and (440) of $\gamma-\mathrm{Fe}_{2} \mathrm{O}_{3}$ crystal plane, respectively (JCPDS 25-1402). This XRD pattern agrees with the previous report, ${ }^{46}$ showing the covering of a very thin oxide layer on zerovalent iron surface. Considering the XRD pattern of as-synthesized $\mathrm{Fe} @ \mathrm{SiO}_{2}$, a broad band at $2 \theta$ in the range between $10^{\circ}$ and $30^{\circ}$ indicated amorphous $\mathrm{SiO}_{2},{ }^{43,47}$ and the diffraction peaks at ca. $45^{\circ}$ could be assigned to the crystalline plane

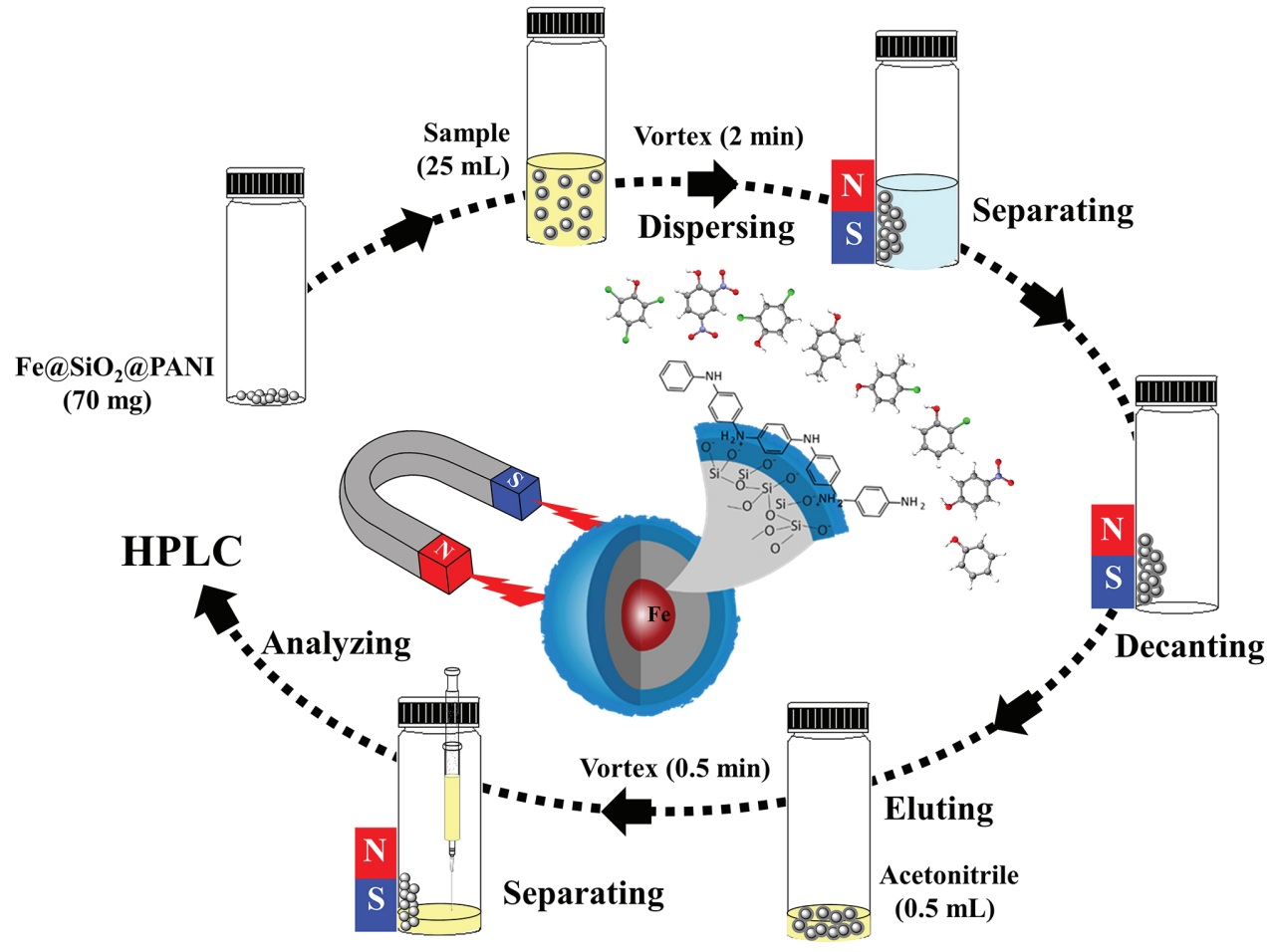

Figure 1. Schematic diagram of the proposed MSPE procedure. 
of zerovalent iron. In addition, the XRD peaks due to the iron oxide phase (at $2 \theta$ of $32^{\circ}, 36^{\circ}, 57^{\circ}$ and $64^{\circ}$ ) were also observed, indicating the coating of silica on zerovalent iron surface..$^{33}$ The crystal planes of (220), (311), (511), and (440) of $\gamma-\mathrm{Fe}_{2} \mathrm{O}_{3}$ at $2 \theta$ of $32^{\circ}, 36^{\circ}, 57^{\circ}$ and $64^{\circ}$, respectively, were observed in the diffraction pattern of Fe@SiO,@PANI. The broad band at $2 \theta$ of $10-30^{\circ}$ due to amorphous phases of both silica and polyaniline was also obviously seen. ${ }^{48}$ However, it is noteworthy that the diffraction peak of zerovalent iron at $45^{\circ}$ was not observed in the XRD pattern of $\mathrm{Fe} @ \mathrm{SiO}_{2} @ \mathrm{PANI}$. This result confirmed success coating of PANI on the zerovalent iron silica surface.

The morphological structure of as-synthesized sorbents was studied by field emission scanning electron microscopy (FESEM). As can be seen in Figure 2a, irregular shape of Fe with particle size of $60 \pm 4 \mathrm{~nm}$ was obtained. The
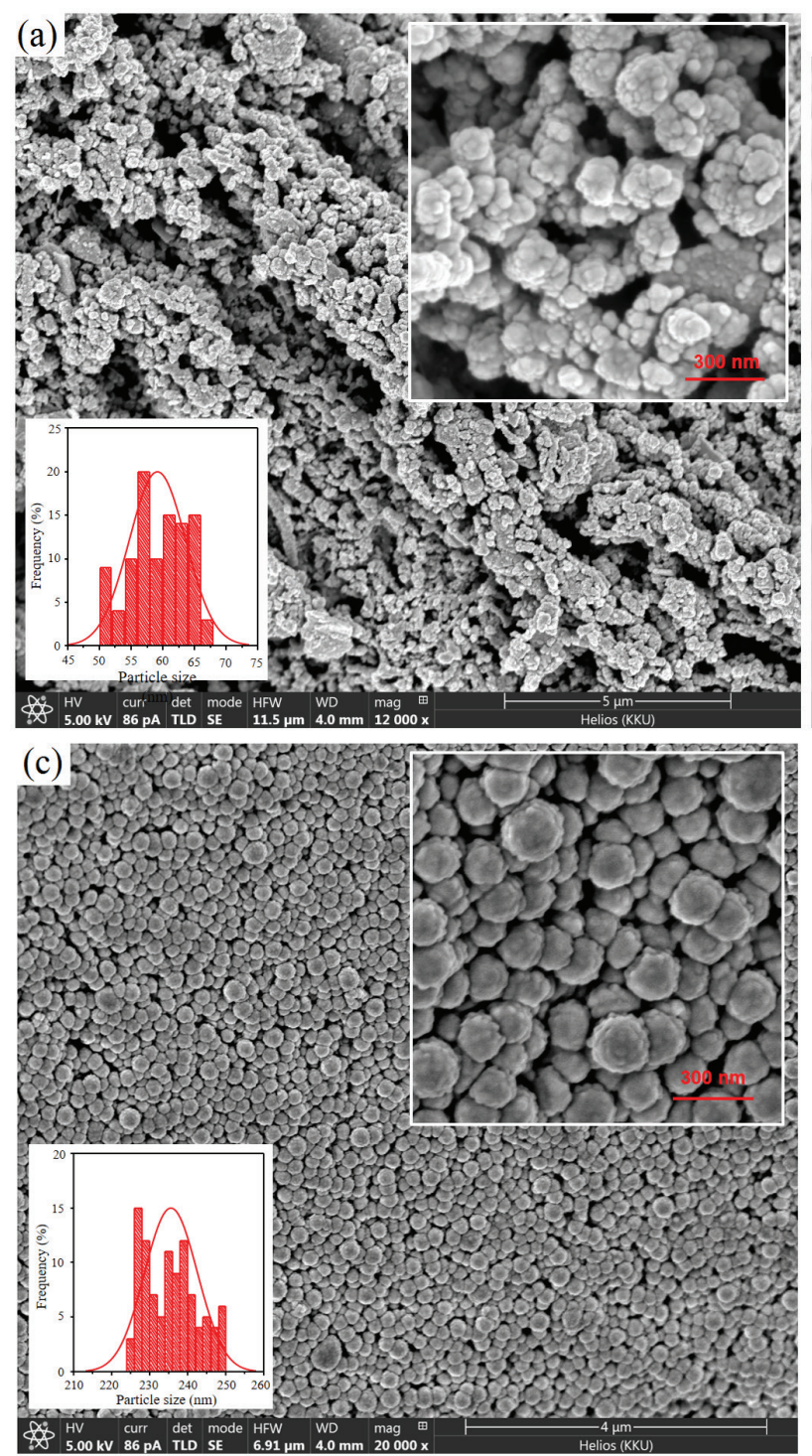

inset histogram revealed the wide size distribution of Fe nanoparticles. The spherical shape of $\mathrm{Fe} @ \mathrm{SiO}_{2}$ with particle size of $190 \pm 15 \mathrm{~nm}$ with its uniform and narrow size distribution was shown in Figure 2 b. The SEM micrograph of $\mathrm{Fe} @ \mathrm{SiO}_{2} @ \mathrm{PANI}$ in Figure 2c shows the linkage-spherical shape due to the effect of polyaniline layer coating. The particle size of $235 \pm 11 \mathrm{~nm}$ was observed. Therefore, the results of FESEM can support the formation of silica coated zerovalent iron as well as its polyaniline coated $\mathrm{Fe} @ \mathrm{SiO}_{2}$.

The elemental analysis indicated that the sorbent contained $12.01 \% \mathrm{C}, 1.72 \% \mathrm{H}$ and $9.3 \% \mathrm{~N}$, which confirmed the existence of polyaniline layer coated on zerovalent iron silica. In addition, the presence of $\mathrm{Fe}, \mathrm{Si}$ and $\mathrm{O}$ contents in $\mathrm{Fe} @ \mathrm{SiO}_{2}$ was confirmed by energy dispersive spectroscopy (EDS) technique (Figure 2d). The results
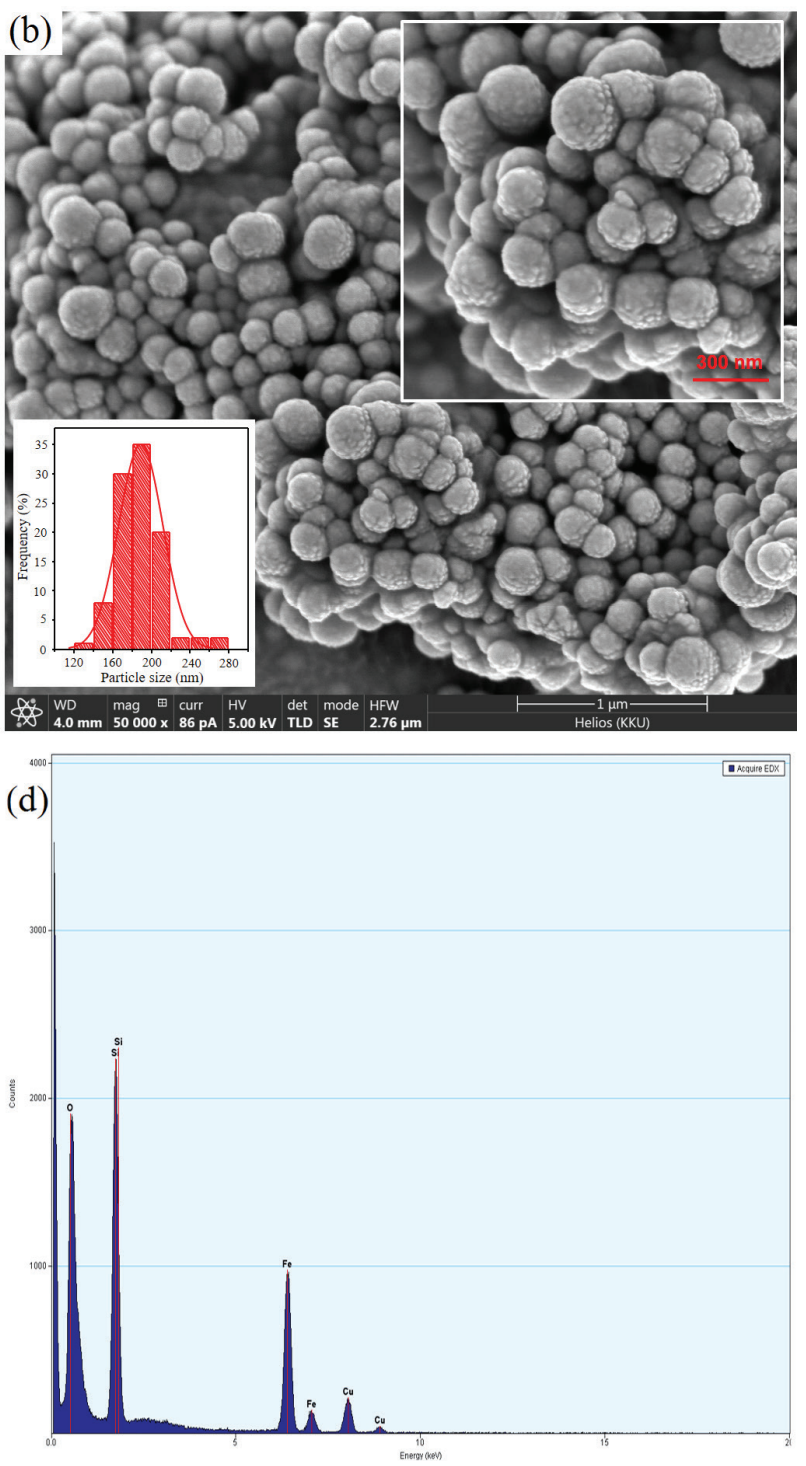

Figure 2. SEM images of (a) as-prepared Fe; (b) $\mathrm{Fe} @ \mathrm{SiO}_{2}$; (c) $\mathrm{Fe} @ \mathrm{SiO}_{2} @ \mathrm{PANI}$ and (d) EDS spectra of Fe@SiO${ }_{2}$. The inset histograms show size distribution of each material. 
showed that as-prepared $\mathrm{Fe} @ \mathrm{SiO}_{2}$ contained $37.5 \% \mathrm{O}$, $43.6 \% \mathrm{Si}$, and $18.9 \% \mathrm{Fe}$, corresponding to the existence of silica coated zerovalent iron.

The Fe@ $\mathrm{SiO}_{2}$ and $\mathrm{Fe} @ \mathrm{SiO}_{2} @ \mathrm{PANI}$ particles were examined by TEM. The TEM image in Figure 3a displayed the formation of spherical silica layer which coated on aggregated zerovalent iron and had silica shell thickness of $20 \mathrm{~nm}$. A well-defined core-shell structure with the zerovalent iron as core, silica as first coating layer and polyaniline as top coating shell was indeed formed (see Figure $3 b)$. These results indicated that the $\mathrm{Fe} @ \mathrm{SiO}_{2} @ \mathrm{PANI}$ was successfully prepared.

The magnetic properties of as-prepared zerovalent iron, $\mathrm{Fe} @ \mathrm{SiO}_{2}$ and $\mathrm{Fe} @ \mathrm{SiO}_{2} @ \mathrm{PANI}$ were measured by VSM in the field range from -10000 to +10000 Oe at room temperature. The magnetic hysteresis curves in Figure S3 (SI section) show the saturation magnetization $\left(\mathrm{M}_{\mathrm{s}}\right)$ values around 92.05, 32.40 and $7.30 \mathrm{emu} \mathrm{g}^{-1}$ for $\mathrm{Fe}$, $\mathrm{Fe} @ \mathrm{SiO}_{2}$ and $\mathrm{Fe} @ \mathrm{SiO}_{2} @ \mathrm{PANI}$, respectively, indicating that these materials exhibit ferromagnetic behavior at room temperature. The $\mathrm{M}_{\mathrm{s}}$ values of as-synthesized nanoparticles are also in agreement with those obtained in the previous reports. ${ }^{48-50}$ The diminution of the $\mathrm{M}_{\mathrm{s}}$ values of $\mathrm{Fe} @ \mathrm{SiO}_{2}$ and $\mathrm{Fe} @ \mathrm{SiO}_{2} @ \mathrm{PANI}$ was compared with the $\mathrm{M}_{\mathrm{s}}$ value of the Fe nanoparticle, it was evident that the high contents of non-magnetic $\mathrm{SiO}_{2}$ and PANI components were coated on the Fe magnetic material. Despite the decrease of the $\mathrm{M}_{\mathrm{s}}$ value of modified $\mathrm{Fe} @ \mathrm{SiO}_{2} @ \mathrm{PANI}$, the sorbent still shows fairly magnetization and is sufficient to be effectively separated from the solution by means of a strong magnet.

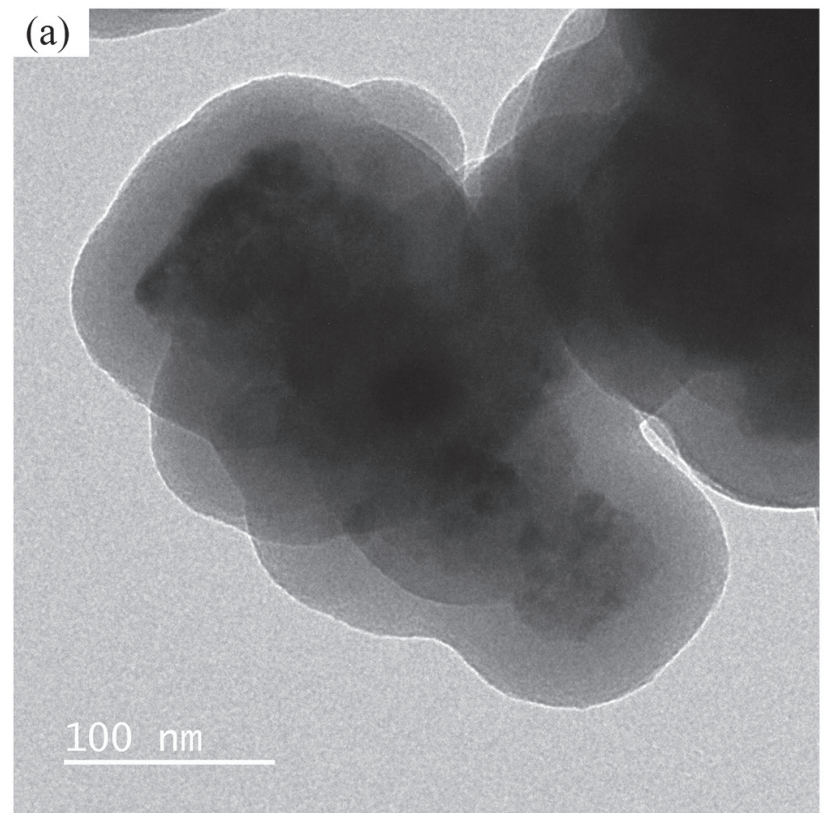

Figure 3. TEM images of (a) $\mathrm{Fe} @ \mathrm{SiO}_{2}$ and (b) $\mathrm{Fe} @ \mathrm{SiO}_{2} @ \mathrm{PANI}$.

Figure 3. TEM images of (a) Fe@

\section{Optimization of the MSPE condition}

In this study, the synthesized $\mathrm{Fe} @ \mathrm{SiO}_{2} @ \mathrm{PANI}$ was applied as magnetic sorbent for extraction of eight phenolic pollutants, including $\mathrm{Ph}$, 4NP, 2CP, 24DNP, 24DMP, 4C3MP, 24DCP and 246TCP, using MSPE procedure. Quantification of the target analytes was performed using HPLC-PDA. To achieve high extraction efficiency for all studied compounds, the effect of experimental variables, such as sorbent amount, sample volume, vortex time, type of desorption solvent, eluent volume, and sample $\mathrm{pH}$ were investigated. The optimization experiments were carried out using a standard solution containing $2.0 \mu \mathrm{g} \mathrm{mL} \mathrm{mL}^{-1}$ of each phenol compound. All experiments were carried out in triplicate. The extraction efficiency of the proposed MSPE method was evaluated using peak area.

\section{Sorbent amount}

The amount of sorbent materials plays a crucial role in the MSPE procedure. Insufficient sorbent amounts result in low extraction efficiency while excess sorbents result in higher consumption of sorbent materials, desorption solvent and extraction time. In this work, the amount of $\mathrm{Fe} @ \mathrm{SiO}_{2} @ \mathrm{PANI}$ was examined in the range from 10 to $90 \mathrm{mg}$, under other conditions as follows: $10 \mathrm{~mL}$ sample volume, $1 \mathrm{~min}$ vortex during adsorption, and $1 \mathrm{~mL}$ acetonitrile with 1 min vortex mixing for desorption. The peak areas of most analytes increased when the sorbent amount was increased from 10 to $70 \mathrm{mg}$ and almost kept constant afterward, except for 24DNP which peak area decreased with increasing the sorbent amount from 50

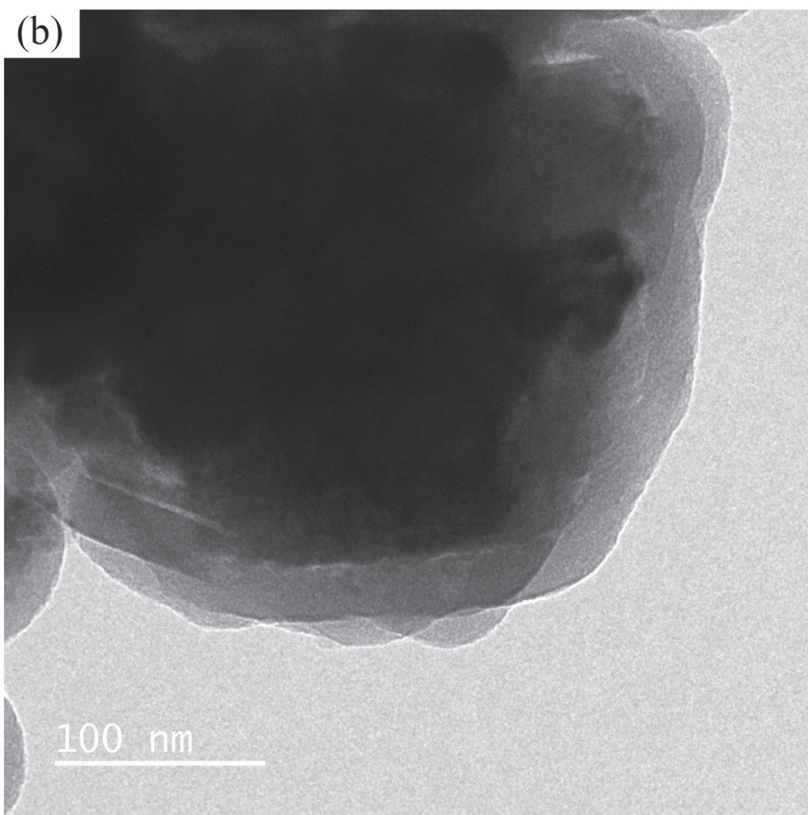


to $90 \mathrm{mg}$ (see Figure 4a). High sorbent amount provided large active sites so that the analytes could form strong interaction with the sorbent. Therefore, complete eluting for some analytes may be difficult using small volume of desorption solvent. Thus, 70 mg of Fe@SiO @ @PANI was selected for further experiments.
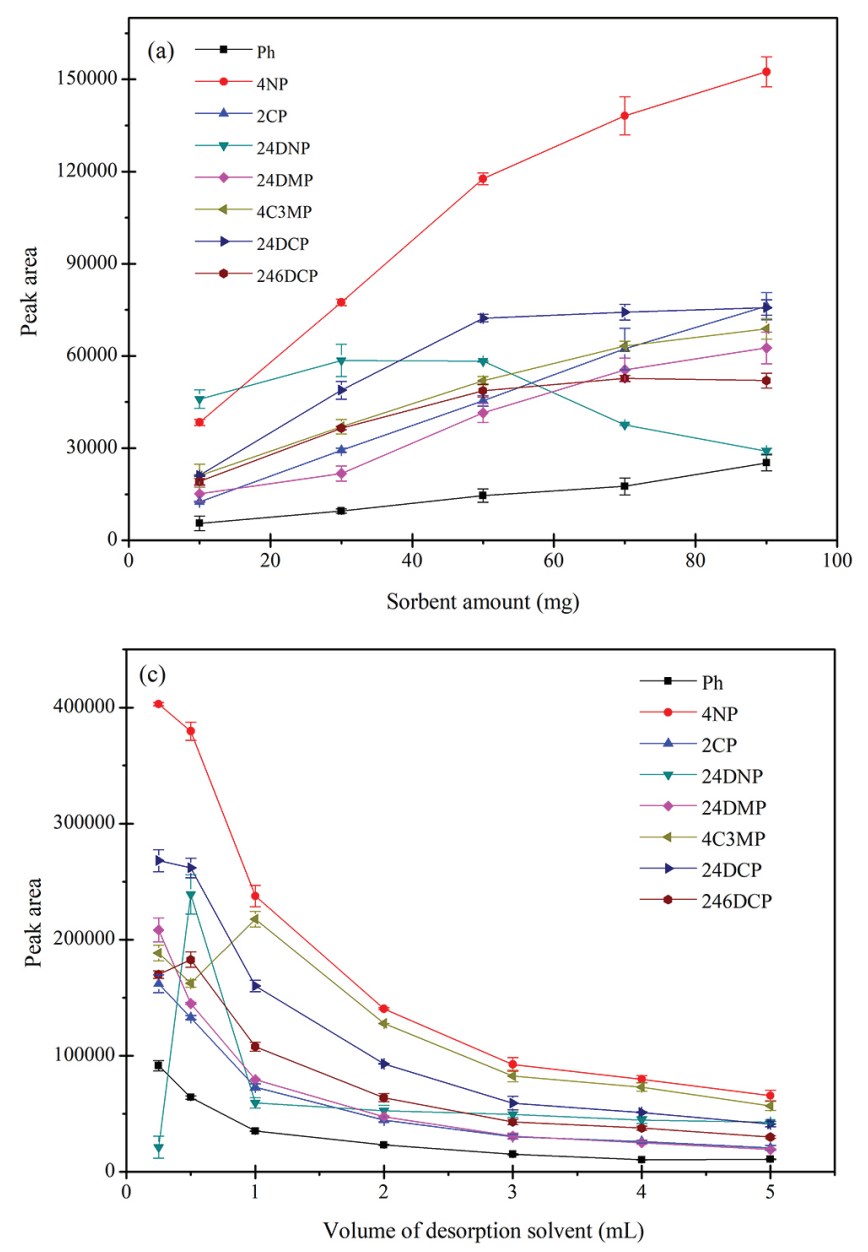

\section{Vortex adsorption time}

MSPE is an equilibrium-based extraction method so that the adsorption time is optimized to ensure quantitative retention of the target analytes along with a short time required for extraction process. In the present work, vortex agitation was applied to accelerate the dispersion of the magnetic
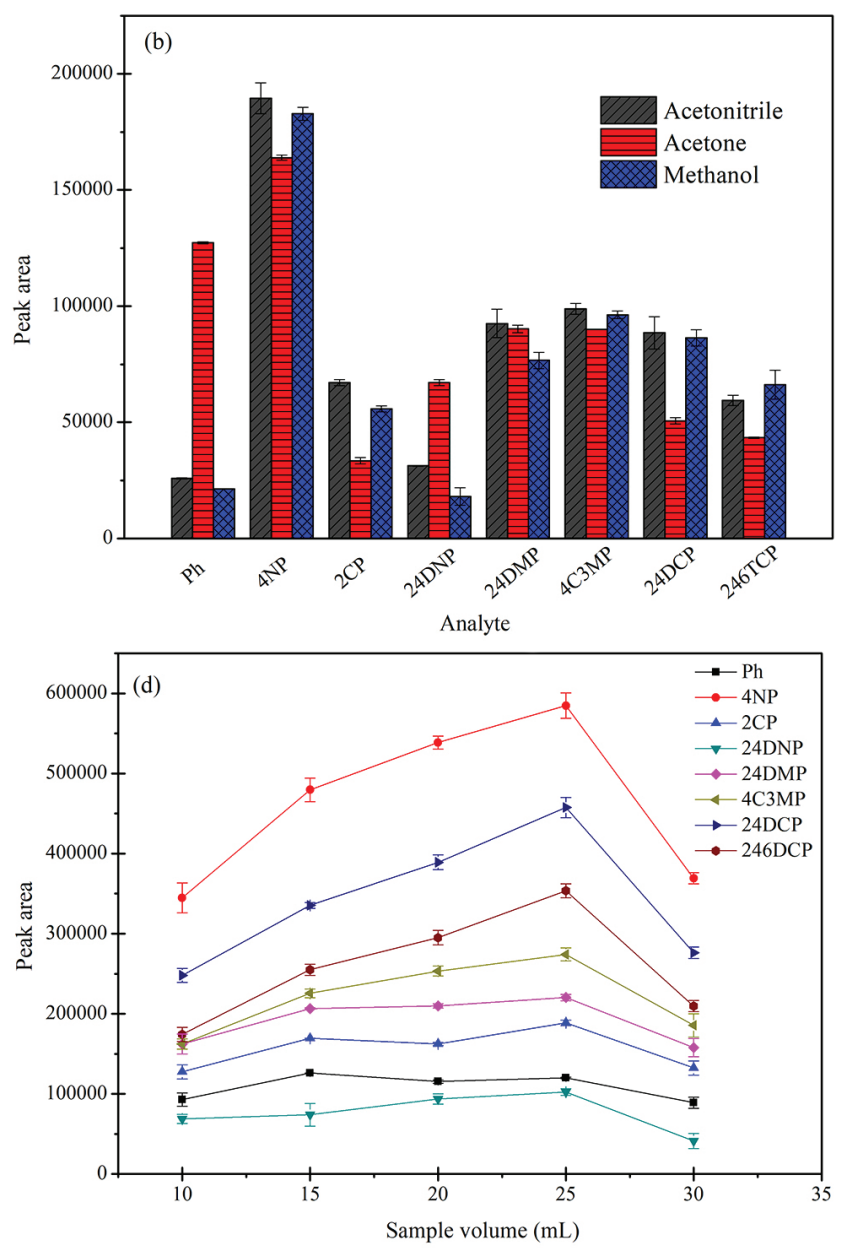

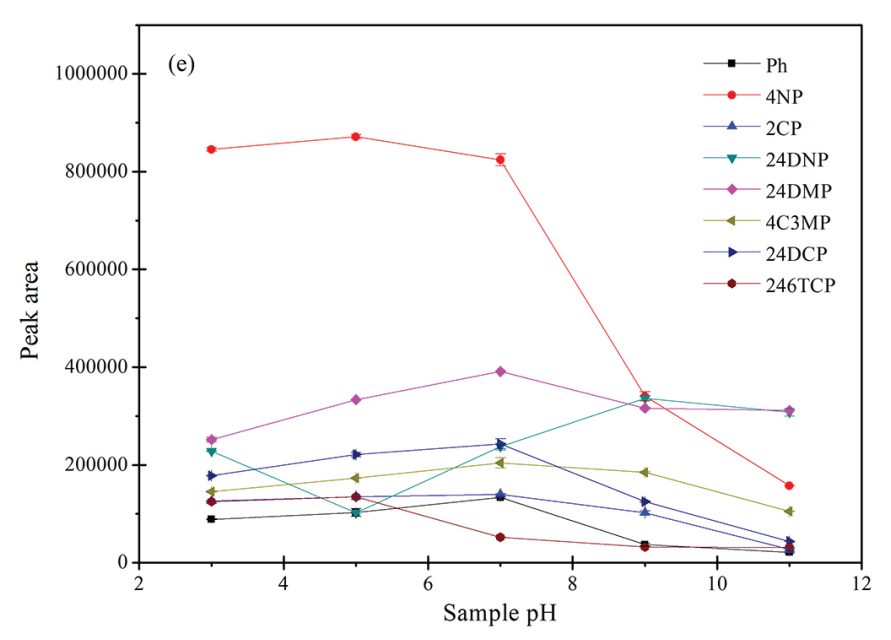

Figure 4. Optimization of MSPE conditions: (a) sorbent amount; (b) type of desorption solvent; (c) volume of desorption solvent; (d) sample volume; (e) sample $\mathrm{pH}$. 
sorbents into the aqueous sample solution. The vortex time during adsorption process was tested from 1 to 5 min using the sorbent amount of $70 \mathrm{mg}, 10 \mathrm{~mL}$ sample volume, $1 \mathrm{~mL}$ acetonitrile as desorption solvent, and desorption time of $1 \mathrm{~min}$. It could be seen that the peak areas of most analytes was approximately constant with vortex time increased from 1 to 4 min, except for 4NP which the peak area increased with increasing the vortex time (see Figure S4, SI section). Applying vortex longer than 4 min, increasing of peak area was obtained for most analytes due to possibility of the analytes to interact with the sorbent. However, in the present work simple and rapid extraction process is expected for quantitative determination of the target phenol compounds. In addition, it could be noted that low precision in term of standard deviation of the peak area was observed for some analytes at $1 \mathrm{~min}$ vortex adsorption time. Therefore, $2 \mathrm{~min}$ was selected to perform the adsorption process.

\section{Desorption time}

The influence of vortex time for desorption process was studied between 0.5-5 min, while other experimental conditions were fixed as follows: 70 mg Fe@ $\mathrm{SiO}_{2} @$ PANI sorbent, sample volume of $10 \mathrm{~mL}$, vortex adsorption time of $2 \mathrm{~min}$, and $1 \mathrm{~mL}$ acetonitrile as desorption solvent. It illustrated that the desorption process was maximized for all target analytes at $0.5 \mathrm{~min}$, and then slightly decreased (see Figure S5, SI section). Therefore, 0.5 min vortex agitation was chosen as optimal time for eluting the studied phenol compounds from the $\mathrm{Fe} @ \mathrm{SiO}_{2} @ \mathrm{PANI}$ sorbent.

\section{Type of desorption solvent}

To select the excellent desorption solvent for complete elution of phenolic compounds from the magnetic sorbent, the polar organic solvents were intensively tested, including methanol, acetonitrile and acetone. The other conditions were controlled as followed: 70 mg Fe@ $\mathrm{SiO}_{2} @ \mathrm{PANI}$ sorbent, $10 \mathrm{~mL}$ sample solution, 2 min vortex mixing during adsorption, $1 \mathrm{~mL}$ desorption solvent, and vortex desorption time of $0.5 \mathrm{~min}$. As it is depicted in Figure 4b, better desorption efficiency for most target analytes was attained using acetonitrile. Acetone also provided high desorption power for $\mathrm{Ph}$ and 24DNP, this could be due to its lower viscosity compared with methanol and acetonitrile. However, interferent peak due to the use of acetone as desorption solvent appeared in the chromatogram. Based on the compatibility with the mobile phase and high desorption efficiency, acetonitrile was selected in this experiment.

\section{Volume of desorption solvent}

The solvent volume is also influencing the sensitivity of the extraction method, as it determines the enrichment factor that can be achieved for the analytes of interest. Thus, the optimization of desorption solvent volume was examined. The volume of acetonitrile was varied from 0.25 to $5 \mathrm{~mL}$ using the $\mathrm{Fe} @ \mathrm{SiO}_{2} @ \mathrm{PANI}$ sorbent amount of $70 \mathrm{mg}$, sample volume of $10 \mathrm{~mL}$, vortex adsorption time of $2 \mathrm{~min}$, and vortex desorption time of $0.5 \mathrm{~min}$. The experimental results are summarized in Figure 4c. It could be seen that $0.5 \mathrm{~mL}$ acetonitrile is sufficient for obtaining satisfactory desorption for all analytes. Using larger desorption solvent volumes, decreasing of peak areas of the analytes was clearly illustrated, which was due to the dilution effect. Therefore, $0.5 \mathrm{~mL}$ acetonitrile was selected for extraction of the analytes from the sorbent in this work.

\section{Sample volume}

In order to achieve high enrichment, an optimum sample volume was investigated. In this work, the aqueous sample solution of $10,15,20,25$ and $30 \mathrm{~mL}$ were extracted under the general procedure of using the $\mathrm{Fe} @ \mathrm{SiO}_{2} @ \mathrm{PANI}$ sorbent amount of $70 \mathrm{mg}$, vortex adsorption time of $2 \mathrm{~min}, 0.5 \mathrm{~mL}$ acetonitrile with $0.5 \mathrm{~min}$ vortex mixing for desorption. As illustrated in Figure 4d, higher extraction recovery in term of peak areas was observed when increasing the sample volumes from 10 to $25 \mathrm{~mL}$, and a slightly decrease was found with further increasing to $30 \mathrm{~mL}$. This could be due to an insufficient homogeneous dispersion of the sorbent in larger volume of the sample. Thus, $25 \mathrm{~mL}$ sample solution was selected for the next optimization experiments.

\section{Sample pH}

The sample solution was examined in the $\mathrm{pH}$ range of 3-11 and the results are shown in Figure 4e. The extraction efficiencies of most analytes were enhanced with increasing the sample $\mathrm{pH}$ from 3 to 7, except for 4NP and 246TCP. These phenolic compounds contained electron withdrawing groups, leading to electron poor in aromatic ring, which can strongly interact toward electron-rich aromatic ring of $\mathrm{Fe} @ \mathrm{SiO}_{2} @ \mathrm{PANI}$ through $\pi$ - $\pi$ interaction. At high $\mathrm{pH}$, the analytes would be ionized and difficult to be extracted, therefore, the extraction efficiencies of most analytes decreased. In the present work, the optimum sample $\mathrm{pH}$ was selected at 7 .

\section{Effect of nylon membrane filter}

Under the above mentioned MSPE condition, the phenolic compounds were then determined by HPLC-PDA. Generally, the extract was filtered through nylon membrane before injecting to the HPLC system. However, polyamide (nylon) was previously reported ${ }^{51,52}$ as efficient sorbent 
Table 1. Analytical features of the proposed MSPE method

\begin{tabular}{|c|c|c|c|c|c|c|c|}
\hline \multirow{2}{*}{ Analyte } & \multirow{2}{*}{ Linear range $/\left(\mu \mathrm{g} \mathrm{mL}^{-1}\right)$} & \multirow{2}{*}{$\mathrm{R}^{2}$} & \multirow{2}{*}{$\mathrm{LOD} /\left(\mu \mathrm{g} \mathrm{mL}^{-1}\right)$} & \multirow{2}{*}{$\mathrm{LOQ} /\left(\mu \mathrm{g} \mathrm{mL} L^{-1}\right)$} & \multirow{2}{*}{$\mathrm{EF}$} & \multicolumn{2}{|c|}{$\mathrm{RSD} / \%$} \\
\hline & & & & & & Intraday $(n=5)$ & Inter-day $(\mathrm{n}=5 \times 3)$ \\
\hline $\mathrm{Ph}$ & $0.016-10.000$ & 0.9926 & 0.005 & 0.016 & 4 & 5.5 & 7.5 \\
\hline $4 \mathrm{NP}$ & $0.012-10.000$ & 0.9979 & 0.001 & 0.012 & 11 & 9.7 & 7.8 \\
\hline $2 \mathrm{CP}$ & $0.060-10.000$ & 0.9984 & 0.020 & 0.060 & 7 & 6.2 & 6.7 \\
\hline 24DNP & $0.016-10.000$ & 0.9980 & 0.005 & 0.016 & 2 & 8.2 & 7.9 \\
\hline 24DMP & $0.033-10.000$ & 0.9980 & 0.010 & 0.033 & 7 & 6.6 & 10.6 \\
\hline 4C3MP & $0.030-10.000$ & 0.9989 & 0.008 & 0.030 & 12 & 5.6 & 6.1 \\
\hline $24 \mathrm{DCP}$ & $0.040-10.000$ & 0.9959 & 0.010 & 0.040 & 13 & 8.2 & 10.8 \\
\hline 246TCP & $0.090-10.000$ & 0.9950 & 0.030 & 0.090 & 15 & 5.6 & 5.1 \\
\hline
\end{tabular}

$\mathrm{R}^{2}$ : coefficient of determination; LOD: limit of detection; LOQ: limit of quantification; EF: enrichment factor; RSD: relative standard deviation; Ph: phenol; 4NP: 4-nitrophenol; 2CP: 2-chlorophenol; 24DNP: 2,4-dinitrophenol; 24DMP: 2,4-dimethylphenol; 4C3MP: 4-chloro-3-methylphenol; 24DCP: 2,4-dichlorophenol; 246TCP: 2,4,6-trichlorophenol.

for extraction of phenolic compounds as its functional group (amide) could interact with phenols through polarpolar interaction. To consider the effect of nylon filter for determination of phenolic compounds, the experiments with filtration using nylon filter were compared with those without filtration. As illustrated in Figure S6 (SI section), the peak areas of all analytes were not noteworthy different. This could be probably due to short filtration time, resulting in no retention of the phenols on nylon structure. Therefore, in the present work the extract was filtered using nylon membrane prior to HPLC analysis in order to protect the analytical column.

\section{Analytical performance}

To verify the method validation of the proposed MSPE procedure, the $\mathrm{Fe} @ \mathrm{SiO}_{2} @ \mathrm{PANI}$ sorbent was applied to extract and determine phenolic compounds, and the results are summarized in Table 1. The calibration curves were obtained by extracting the mixed standard solutions of eight phenolic compounds ranging from $0.012-10.000 \mu \mathrm{gL}^{-1}$. Linearity was achieved with the coefficients of determination $\left(\mathrm{R}^{2}\right)$ in the range of 0.9926-0.9989. The limits of detection (LOD) and quantification (LOQ), which were defined as the signal to noise ratios of 3 and 10, were 0.001-0.030 and $0.012-0.090 \mu \mathrm{g} \mathrm{mL}^{-1}$, respectively. The enrichment factors, calculated as the slope ratio of the calibration graphs with and without MSPE, were in the range of $2-15$. The precision of the proposed method was evaluated by analyzing the mixed standard solutions of phenolic compounds, at concentration of $0.5 \mu \mathrm{g} \mathrm{mL}^{-1}$ each, in one day and day-to-day. It was observed that the relative standard deviations (RSD) of the peak area were less than
10 and $11 \%$ for intraday $(n=5)$ and inter-day $(n=5 \times 3)$, respectively. The chromatograms in Figure 5 reveal the practical enrichment of phenolic compounds attained by applying MSPE method.

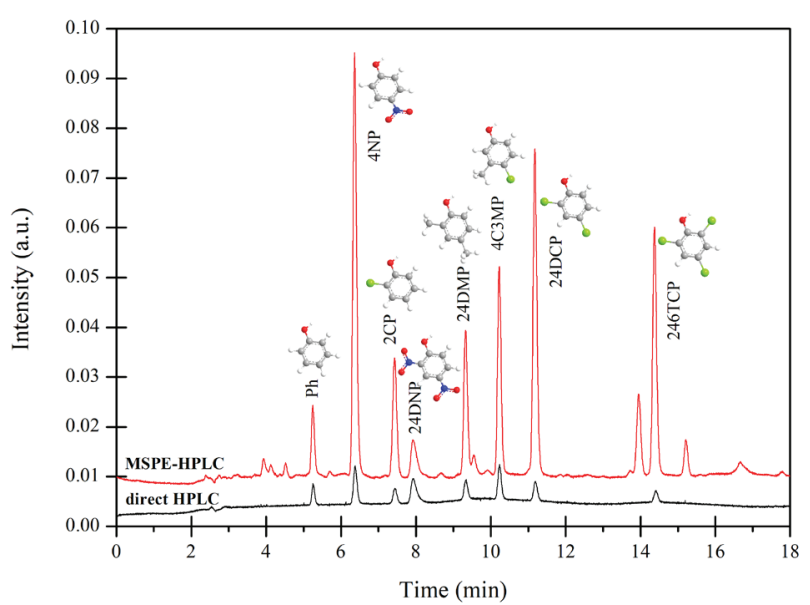

Figure 5. Chromatograms of phenolic pollutant standards obtained by direct HPLC and after concentrated by MSPE procedure.

Retention mechanism of the studied phenolic pollutants on $\mathrm{Fe} @ \mathrm{SiO}_{2} @ \mathrm{PANI}$ sorbent was expected through different kinds of interactions based on the structural features of PANI, including hydrophobicity, $\pi$-conjugated structure and polar groups. PANI can form hydrogen bond with hydroxyl group of phenols. ${ }^{53,54}$ An electrostatic interaction between nitro group of the phenol derivatives and PANI could also be formed, which can be explained by nitrophenol rings with the positive charges can bind with polyaniline rings acting as negative charges through electrostatic interaction. ${ }^{13}$ In addition, aromatic groups of phenol and PANI can afford abundant $\pi-\pi$ interaction. ${ }^{55}$ 
Reusability of $\mathrm{Fe} @ \mathrm{SiO}_{2} @ \mathrm{PANI}$ sorbent

The sustainable material is recently one of attracted alternative sorbent as it offers some advantages, including less waste producing, low environmental impact, cost effectiveness, providing high efficiency, and being reusable. In this report, the reusability of the $\mathrm{Fe} @ \mathrm{SiO}_{2} @ \mathrm{PANI}$ sorbent was intensively studied to evaluate the stability of as-prepared sorbent for the repeated usage in several cycles. The recycling process was started after the sorbent was regenerated with $15 \mathrm{~mL}$ of methanol on vortex mixer, and then dried at $80^{\circ} \mathrm{C}$ for $2 \mathrm{~h}$. The probability for reusing of the sorbent was observed for up to 16 cycles without significant loss of extraction performance, as shown in Figure S7 (SI section).

\section{Application to real samples}

The proposed MSPE method using as-synthesized $\mathrm{Fe} @ \mathrm{SiO}_{2} @ \mathrm{PANI}$ as sorbent coupled with HPLC-PDA was applied to the analysis of environmental waters (collected from different rivers and reservoirs) and wastewaters (from university, hospital and textile industry). The results presented that phenols were not detected in the studied environmental water samples. However, 24DNP was found in two wastewater samples collected from hospital, and textile industry with detectable values of 0.039 and $0.061 \mu \mathrm{g} \mathrm{mL}^{-1}$, respectively. To determine the accuracy of the method, the recovery experiments were carried out by spiking water samples with the phenolic compound standards at 2 concentration levels. The satisfactory recoveries of eight phenolic compounds were in the range of 83.4-118.9\%, as summarized in Table S1 (SI section).

Comparison of the $\mathrm{Fe} @ \mathrm{SiO}_{2} @ \mathrm{PANI}$ based MSPE with other methods

To demonstrate the potential use of the $\mathrm{Fe} @ \mathrm{SiO}_{2} @$ PANI as sorbent in the MSPE method, the proposed procedure was compared with some other reported methods for the determination of phenol compounds in various sample matrices. The experimental conditions and analytical results obtained by different sample preparation procedures are listed in Table 2. The developed method is reliable for a variety of phenol pollutants. Comparing with the previous methods using PANI-based materials, the LODs and LOQs is comparable to those obtained by the MSPE using $\mathrm{PANI} / \mathrm{SiO}_{2} / \mathrm{Ni} \mathrm{NPs}$ as sorbent, ${ }^{56}$ however, the proposed method offers lower consumption of sample volume with simple extraction conditions compared with previous report. ${ }^{39}$ In addition, a shorter extraction time (time consumption in both adsorption and desorption processes) was another advantage of this work when compared to those reported by others. ${ }^{7,39,56}$ Considering the Fe@SiO $@$ PANI sorbent proposed in this work, it can be synthesized easily with facile condition at ambient temperature using a simple process, and no hydrothermal or complicated equipment is required. The advantages of the developed MSPE process, together with its simple and facile preparation, give the $\mathrm{Fe} @ \mathrm{SiO}_{2} @ \mathrm{PANI}$ a choice of sorbent for pretreatment of phenol pollutants in various sample matrices.

\section{Conclusions}

An efficient $\mathrm{Fe} @ \mathrm{SiO}_{2} @$ PANI magnetic sorbent was successfully prepared by simple stepwise process including sol-gel followed by oxidative polymerization methods. This synthesized sorbent was characterized and used as sorbent in MSPE procedure for the determination of eight phenolic pollutants. The optimum conditions for MSPE coupled with HPLC-PDA were investigated. The versatile zerovalent iron-silica particles coated with PANI exhibit multiple interactions for the target analytes showing potential feature for extraction of the phenolic pollutants from environmental and wastewater matrix. The proposed method offers good extraction recovery, high precision and accuracy with possibility of fast, and simple extraction process. The reusability of $\mathrm{Fe} @ \mathrm{SiO}_{2} @ \mathrm{PANI}$ sorbent up to sixteen cycles is possible without any significant reduction of extraction performance.

\section{Supplementary Information}

Supplementary information is available free of charge at http://jbcs.sbq.org.br as PDF file.

\section{Acknowledgments}

The authors gratefully acknowledge financial support from the Materials Chemistry Research Center, Khon Kaen University, and Center of Excellence for Innovation in Chemistry (PERCH-CIC), Ministry of Higher Education, Science, Research and Innovation (Implementation Unit-IU, Khon Kaen University). R. B. thanks the Thailand Research Fund (TRF) and Khon Kaen University for supporting the TRF Research Scholar (grant No. RSA5980034). The TRF Distinguished Research Professor Award (DPG6080002) to Prof Kate Grudpan is also acknowledged. 
Table 2. Comparison of the proposed MSPE with other reported methods

\begin{tabular}{|c|c|c|c|c|c|}
\hline Method & Analyte & Sample matrix & Extraction condition & $\begin{array}{l}\text { Analytical } \\
\text { technique }\end{array}$ & Analytical performance \\
\hline DMSPE $^{56}$ & $\begin{array}{c}\text { 2-NP, } \mathrm{Ph}, p \text {-cresol, } \\
\text { carvacrol, 2-tert- } \\
\text { butylphenol, mequinol, } \\
\text { 4-CP, resorcinol }\end{array}$ & water & $\begin{array}{c}\text { sorbent: } 20 \mathrm{mg} \text { PANI } / \mathrm{SiO}_{2} / \mathrm{Ni} \mathrm{NPs} \\
\text { sample volume: } 5 \mathrm{~mL} ; \\
\text { adsorption: } 30 \text { s sonication }+5 \mathrm{~min} \\
\text { vortex; } \\
\text { eluent: } 40 \mu \mathrm{L} \mathrm{ACN} \\
\text { desorption: } 11.5 \mathrm{~min} \text { sonication }\end{array}$ & GC-FID & $\begin{array}{l}\text { linear range: } 0.02-100 \mathrm{mg} \mathrm{L}^{-1} \\
\text { LOD: } 10-23 \mu \mathrm{g} \mathrm{L}^{-1} \\
\text { LOQ: } 33-77 \mu \mathrm{g} \mathrm{L}^{-1} \\
\text { R: } 96-105 \% \\
\text { RSD: }<4 \%\end{array}$ \\
\hline
\end{tabular}

\begin{tabular}{|c|c|c|c|c|c|}
\hline $\mathrm{MSPE}^{39}$ & $\begin{array}{c}\text { bisphenol A, } \\
\text { tetrabromobisphenol A, } \\
\text { 4-nonylphenol }\end{array}$ & water & $\begin{array}{l}\text { sorbent: } 60 \text { mg PANI@ } \mathrm{SiO}_{2} @ \mathrm{Fe} \text {; } \\
\text { sample volume: } 60 \mathrm{~mL} \text {; } \\
\text { adsorption: } 60 \text { min shaking on a } \\
\text { temperature-controlled water-bath; } \\
\text { eluent: } 7.5 \mathrm{~mL} \mathrm{MeOH} \mathrm{(dried} \mathrm{with} \\
\mathrm{N}_{2} \text { at } 40^{\circ} \mathrm{C} \text { and redissolved with } \\
\quad 200 \mu \mathrm{L} \mathrm{MeOH})\end{array}$ & HPLC-UV & $\begin{array}{c}\text { linear range: } 0.05-300 \mu \mathrm{g} \mathrm{L}^{-1} \\
\text { LOD: } 0.009-0.073 \mu \mathrm{g} \mathrm{L}^{-1} \\
\text { R: } 92.9-98.9 \% \\
\text { RSD: }<3.73 \%\end{array}$ \\
\hline
\end{tabular}

\begin{tabular}{ccc}
\hline & \\
& & \\
& & \\
$\mathrm{SB} \mu-\mathrm{SPE}^{7}$ & $246 \mathrm{DCP}, 23 \mathrm{DCP}, 26 \mathrm{DCP}$, & \\
& $4 \mathrm{tOP}, 2 \mathrm{~B} 4 \mathrm{CP}$
\end{tabular}

sorbent: $20 \mathrm{mg}$ 4-phenyl-1,2,3triazole functionalized SBA-15 sealed inside a PP bag; adsorption: 15 min stirring; eluent: $300 \mu \mathrm{L}$ ethyl acetate; desorption: 20 min sonication

$\begin{array}{cc}\text { linear range: } 1-600 \mu \mathrm{g} \mathrm{L}^{-1} \\ \text { GC-MS } & \text { LOD: } 0.23-0.37 \mu \mathrm{g} \mathrm{L}^{-1} \\ & \text { R: } 88.5-99.2 \% \\ \text { RSD: } 2.3-7.5 \%\end{array}$

sorbent: polyvinylidene fluoride matrix disks containing entrapped Online MMD-
$\mathrm{SPE}^{3}$ UiO-66- $\mathrm{NH}_{2}$ MOFs; sample volume: $1.5 \mathrm{~mL}$; eluent: $0.3 \mathrm{~mL}$ acetone; desorption flow rate: $0.5 \mathrm{~mL} \mathrm{~min}^{-1}$

linear range: $0.5-500 \mu \mathrm{g} \mathrm{L}{ }^{-1}$
LOD: $0.1-0.2 \mu \mathrm{g} \mathrm{L}^{-1}$
R: $90-98 \%$
RSDC-DAD $3.9-5.7 \%$ (intraday),
$4.7-5.7 \%$ (inter-day)

sorbent: $5 \mathrm{mg}$ graphene aerosols filled in 2-mL syringe; Ph, 4NP, 2NP, 3MP, 4C3MP, 24DCP, In-syringe extraction $^{5}$ 2M46DNP, 246TCP, PCP

river water sample volume: $40 \mathrm{~mL}$; adsorption: $20 \mathrm{~min}$; eluent: $200 \mu \mathrm{L}$ ACN linear range: $0.05-20 \mu \mathrm{g} \mathrm{L}^{-1}$ LOD: $0.016-0.075 \mu \mathrm{g} \mathrm{L}^{-1}$ LOQ: $0.053-0.250 \mu \mathrm{g} \mathrm{L}^{-1}$

R: $96.3-102.4 \%$ RSD: $<5.4 \%$
HPLC-UV sorbent: 30 mg NH${ }_{2}$-MIL-53(Al)

$$
\text { MOF; }
$$

$\mathrm{Ph}$, 4NP, 24DNP,

VA-D- $\mu-$ SPE $^{4}$ 2NP, 4C3MP, 24DCP, 2M46DNP, 246TCP

water sample volume: $10 \mathrm{~mL}$; eluent: $1.5 \mathrm{~mL}$ ACN-HOAc $(9.5: 0.5 \mathrm{v} / \mathrm{v})$; desorption: $10 \mathrm{~s}$ vortex

\begin{tabular}{|c|c|c|c|c|c|}
\hline $\begin{array}{l}\text { MSPE } \\
\text { (this study) }\end{array}$ & $\begin{array}{c}\mathrm{Ph}, 4 \mathrm{NP}, 2 \mathrm{CP}, 24 \mathrm{DNP}, \\
24 \mathrm{DMP}, 4 \mathrm{C} 3 \mathrm{MP}, 24 \mathrm{DCP}, \\
246 \mathrm{TCP}\end{array}$ & water & $\begin{array}{c}\text { sorbent: } 70 \text { mg Fe@ } \mathrm{SiO}_{2} @ \mathrm{PANI} \\
\text { sample volume: } 10 \mathrm{~mL} \\
\text { adsorption: } 2 \mathrm{~min} \text { vortex; } \\
\text { eluent: } 0.5 \mathrm{~mL} \text { ACN; } \\
\text { desorption: } 30 \mathrm{~s} \text { vortex }\end{array}$ & HPLC-DAD & $\begin{array}{l}\text { linear range: } 0.012-10.000 \mu \mathrm{g} \mathrm{mL}^{-1} \\
\text { LOD: } 0.001-0.030 \mu \mathrm{gL}^{-1} \\
\text { LOQ: } 0.012-0.090 \mu \mathrm{gL}^{-1} \\
\text { R: } 83.4-118.5 \% \\
\text { RSD: }<11 \%\end{array}$ \\
\hline
\end{tabular}

DMSPE: dispersive micro-solid-phase extraction; 2-NP: 2-nitrophenol; Ph: phenol; 4-CP: 4-chlorophenol; PANI: polyaniline; NPs: nitrophenols; ACN: acetonitrile; GC-FID: gas chromatography-flame ionization detection; LOD: limit of detection; LOQ: limit of quantification; R: recovery; RSD: relative standard deviation; MSPE: magnetic solid phase extraction; HPLC-UV: high performance liquid chromatography-ultraviolet detection; SB- $\mu$-SPE: stir bar-supported micro-solid-phase extraction; 24DCP: 2,4-dichlorophenol; 23DCP: 2,3-dichlorophenol; 26DCP: 2,6-dichlorophenol; 246TCP: 2,4,6-trichlorophenol; 26DTB4MP: 2,6-di-tert-butyl-4-methylphenol; 4tOP: 4-tert-octylphenol; 2B4CP: 2-benzyl-4-chlorophenol; SBA-15: Santa Barbara amorphous-15; PP: polypropylene; GC-MS: gas chromatography-mass spectrometry; MMD-SPE: mixed-matrix disks solid-phase extraction; 4NP: 4-nitrophenol; 2CP: 2-chlorophenol; 24DNP: 2,4-dinitrophenol; 2NP: 2-nitrophenol; 24DMP: 2,4-dimethylphenol; 4C3MP: 4-chloro-3-methylphenol; 24DCP: 2,4-dichlorophenol; MOF: metal organic framework; HPLC-DAD: high performance liquid chromatography-photodiode array detection; 3MP: 3-methylphenol; 2M46DNP: 2-methyl-4,6-dinitrophenol; 246TCP: 2,4,6-trichlorophenol; PCP: phencyclidine; VA-D- $\mu$-SPE: vortex-assisted dispersive micro-solid-phase extraction; MIL: Matériaux de 1'Institut Lavoisier. 


\section{References}

1. Zhang, P. P.; Shi, Z. G.; Feng, Y. Q.; Talanta 2011, 85, 2581.

2. Tang, S.; Lin, X. H.; Li, S. F. Y.; Lee, H. K.; J. Chromatogr. A 2014, 1373, 31.

3. Ghani, M.; Picó, M. F. F.; Salehinia, S.; Cabello, C. P.; Maya, F.; Berlier, G.; Saraji, M.; Cerdà, V.; Palomino, G. T.; J. Chromatogr. A 2017, 1488, 1.

4. Boontongto, T.; Siriwong, K.; Burakham, R.; Chromatographia 2018, 81, 735 .

5. Tang, S.; Sun, J.; Xia, D.; Zang, B.; Gao, Y.; Chen, C.; Shen, W.; Lee, H. K.; Talanta 2019, 195, 165.

6. Liu, Y.; Huang, Y.; Chen, G.; Huang, J.; Zheng, J.; Xu, J.; Liu, S.; Qiu, J.; Yin, L.; Ruan, W.; Zhu, F.; Ouyang, G.; Anal. Chim. Acta 2018, 1015, 20.

7. Tanimu, A.; Jillani, S. M. S.; Alluhaidan, A. A.; Ganiyu, S. A.; Alhooshani, K.; Talanta 2019, 194, 377.

8. Chisvert, A.; Cárdenas, S.; Lucena, R.; TrAC, Trends Anal. Chem. 2019, 112, 226.

9. Khezeli, T.; Daneshfar, A.; TrAC, Trends Anal. Chem. 2017, 89, 99.

10. Huang, D.; Deng, C.; Zhang, X.; Anal. Methods 2014, 6, 7130.

11. Zhou, Q.; Lei, M.; Li, J.; Zhao, K.; Liu, Y.; J. Chromatogr. A 2016, 1441, 1 .

12. Tahmasebi, E.; Yamini, Y.; Mehdinia, A.; Rouhi, F.; J. Sep. Sci. 2012, 35, 2256.

13. Zhang, W. F.; Zhang, Y. H.; Jiang, Q.; Zhao, W. J.; Yu, A.; Chang, H.; Lu, X. M.; Xie, F. X.; Ye, B. X.; Zhang, S. S.; Anal. Chem. 2016, 88, 10523.

14. Zhou, L. C.; Ji, L. Q.; Ma, P. C.; Shao, Y. M.; Zhang, H.; Gao, W. J.; Li, Y. F.; J. Hazard. Mater. 2014, 265, 104.

15. Ma, J.; Jiang, L.; Wu, G.; Xia, Y.; Lu, W.; Li, J.; Chen, L.; J. Chromatogr. A 2016, 1466, 12.

16. Chen, L.; Zhang, M. Y.; Fu, F. F.; Li, J. G.; Lin, Z.; J. Chromatogr. A 2018, 1567, 136.

17. Ma, J.; Yao, Z.; Hou, L.; Lu, W.; Yang, Q.; Li, J.; Chen, L.; Talanta 2016, 161, 686.

18. Ma, J.; Wu, G.; Li, S.; Tan, W.; Wang, X.; Li, J.; Chen, L.; J. Chromatogr. A 2018, 1553, 57.

19. Liu, Z. G.; Wang, Y.; Deng, R.; Yang, L. Y.; Yu, S. H.; Xu, S. P.; Xu, W. Q.; ACS Appl. Mater. Interfaces 2016, 8, 14160.

20. Li, D.; Ma, X.; Wang, R.; Yu, Y.; Anal. Bioanal. Chem. 2017, 409, 1165.

21. Wu, X.; Li, Y. R.; Zhu, X. L.; He, C. Y.; Wang, Q.; Liu, S. R.; Talanta 2017, 162, 57.

22. Bagheri, A. R.; Arabi, M.; Ghaedi, M.; Ostovan, A.; Wang, X.; Li, J.; Chen, L.; Talanta 2019, 195, 390.

23. Wu, X.; Wang, X.; Lu, W.; Wang, X.; Li, J.; You, H.; Xiong, H.; Chen, L.; J. Chromatogr. A 2016, 1435, 30.

24. Fu, F. L.; Dionysiou, D. D.; Liu, H.; J. Hazard. Mater. 2014, 267, 194.
25. Mao, Z.; Wu, Q.; Wang, M.; Yang, Y.; Long, J.; Chen, X.; Nanoscale Res. Lett. 2014, 9, 501.

26. Jamei, M. R.; Khosravi, M. R.; Anvaripour, B.; Asia-Pac. J. Chem. Eng. 2013, 8, 767.

27. Li, Y.; Zhang, Y.; Li, J.; Zheng, X.; Environ. Pollut. 2011, 159, 3744.

28. Bhaumik, M.; Maity, A.; Gupta, V. K.; J. Colloid Interface Sci. 2017, 506, 403.

29. Tosco, T.; Papini, M. P.; Viggi, C. C.; Sethi, R.; J. Cleaner Prod. 2014, 77, 10.

30. Xue, W. J.; Huang, D. L.; Zeng, G. M.; Wan, J.; Cheng, M.; Zhang, C.; Hu, C. J.; Li, J.; Chemosphere 2018, 210, 1145.

31. Tso, C. P.; Shih, Y. H.; Water Res. 2015, 72, 372.

32. Sikder, M. T.; Tanaka, S.; Saito, T.; Kurasaki, M.; J. Environ. Chem. Eng. 2014, 2, 370.

33. Lu, H. J.; Dong, J.; Zhang, M. Y.; Hu, W. H.; Wen, C. Y.; Yang, C. G.; Wu, Y.; Colloids Surf., A 2018, 558, 271.

34. Asgharinezhad, A. A.; Ebrahimzadeh, H.; Mirbabaei, F.; Mollazadeh, N.; Shekari, N.; Anal. Chim. Acta 2014, $844,80$.

35. Arnnok, P.; Patdhanagul, N.; Burakham, R.; Talanta 2017, 164, 651.

36. Yang, X. L.; Qiao, K. X.; Ye, Y. R.; Yang, M. Y.; Li, J.; Gao, H. X.; Zhang, S. B.; Zhou, W. F.; Lu, R. H.; Anal. Chim. Acta 2016, 934, 114.

37. Lien, Y. H.; Wu, T. M.; J. Colloid Interface Sci. 2008, 326, 517.

38. Santra, S.; Tapec, R.; Theodoropoulou, N.; Dobson, J.; Hebard, A.; Tan, W. H.; Langmuir 2001, 17, 2900.

39. Zhou, Q.; Yuan, Y.; Wu, Y.; Liu, Y.; J. Sep. Sci. 2017, 40, 4032.

40. Huang, D. L.; Chen, G. M.; Zeng, G. M.; Xu, P.; Yan, M.; Lai, C.; Zhang, C.; Li, N. J.; Cheng, M.; He, X. X.; He, Y.; Water, Air, Soil Pollut. 2015, 226, 375.

41. Abu-Thabit, N. Y.; J. Chem. Educ. 2016, 93, 1606.

42. Mahmoud, M. E.; Saad, E. A.; Soliman, M. A.; Abdelwahab, M. S.; J. Environ. Chem. Eng. 2017, 5, 5157.

43. Ding, H. L.; Zhang, Y. X.; Wang, S.; Xu, J. M.; Xu, S. C.; Li, G. H.; Chem. Mater. 2012, 24, 4572.

44. Abolghasemi, M. M.; Arsalani, N.; Yousefi, V.; Arsalani, M.; Piryaei, M.; J. Sep. Sci. 2016, 39, 956.

45. Rezvani, M.; Asgharinezhad, A. A.; Ebrahimzadeh, H.; Shekari, N.; Microchim. Acta 2014, 181, 1887.

46. Sun, Y. P.; Li, X. Q.; Cao, J. S.; Zhang, W. X.; Wang, H. P.; Adv. Colloid Interface Sci. 2006, 120, 47.

47. Fan, F. Y.; Pan, D. Q.; Wu, H. Y.; Zhang, T. J.; Wu, W. S.; Ind. Eng. Chem. Res. 2017, 56, 2221.

48. Fleaca, C. T.; Dumitrache, F.; Morjana, I.; Niculescu, A. M.; Sandu, I.; Ilie, A.; Stamatin, I.; Iordache, A.; Vasile, E.; Prodan, G.; Appl. Surf. Sci. 2016, 374, 213.

49. Lee, Y. C.; Lee, K. B.; Hwang, Y. H.; Andersen, H. R.; Kim, B. W.; Lee, S. Y.; Choi, M. H.; Park, J. Y.; Han, Y. K.; Oh, Y. K.; Huh, Y. S.; RSC Adv. 2014, 4, 4122. 
50. Mero, O.; Sougrati, M. T.; Jumas, J. C.; Margel, S.; Langmuir 2014, 30, 9850.

51. Bagheri, H.; Aghakhani, A.; Baghernejad, M.; Akbarinejad, A.; Anal. Chim. Acta 2012, 716, 34.

52. Reyes-Gallardo, E. M.; Lucena, R.; Cardenas, S.; Valcarcel, M.; Microchem. J. 2016, 124, 751.

53. Yang, K.; Wu, W. H.; Jing, Q. F.; Zhu, L. Z.; Environ. Sci. Technol. 2008, 42, 7931.
54. Reynisson, J.; McDonald, E.; J. Comput.-Aided Mol. Des. 2004, $18,421$.

55. Mukherjee, A.; Dixit, K.; Sarmab, S. P.; Desiraju, G. R.; IUCrJ 2014, 1, 228.

56. Babaee, S.; Daneshfar, A.; J. Sep. Sci. 2016, 39, 2508.

Submitted: June 13, 2020

Published online: August 18, 2020 